\title{
The effects of electrodermal lability and stimulus intensity on skin conductance habituation: A preliminary report
}

\author{
GERHARD VOSSEL and RAINER ROSSMANN \\ University of Mainz, 6500 Mainz, West Germany
}

\begin{abstract}
A between-subjects design $(\mathrm{N}=60)$ was used to investigate the effects of electrodermal lability and auditory stimulus intensity on habituation of the skin conductance response (SCR). Subjects were subdivided into "labile" and "stabile" groups on the basis of frequency of nonspecific electrodermal responses during the prestimulation period. They received 20 presentations of a $1,000-\mathrm{Hz}$ tone of $15,35,65,75,95$, or $110 \mathrm{~dB}$. There were significant effects of stimulus intensity on all three habituation measures (number of trials to habituation, reciprocal of SCR frequency to the first 10 stimuli, slope of the regression of SCR amplitude on log stimulus number). Additionally, significant effects of lability on the number of trials to habituation and the slope scores were found. Conclusions about the direction of influence of lability and intensity on SCR habituation, however, differed, depending on the habituation measure used.
\end{abstract}

Sokolov's (1963) neuronal model of the orienting response (OR) implies a nonmonotonic relationship between stimulus intensity and habituation of the OR. Habituation should be slower with weak stimuli near threshold than with somewhat stronger stimuli. With stimulus intensity increasing further, OR habituation should be slower, and with very strong stimuli, a defense response (DR) that shows little or no habituation should be elicited. Slower habituation with weak stimuli is of particular interest, since it is not expected from the "dual-process" theory as formulated by Thompson and his colleagues (Groves \& Thompson, 1970; Thompson \& Spencer, 1966). Thompson and Spencer stated that habituation was an inverse function of stimulus intensity: "The weaker the stimulus, the more rapid and/or pronounced is habituation"' (p. 19).

Findings concerning the effects of stimulus intensity on habituation of the skin conductance response (SCR) are, however, not conclusive. Specifically, the effects of weak stimuli are contradictory (e.g., Jackson, 1974; Raskin, Kotses, \& Bever, 1969; Schandry, 1978; Turpin \& Siddle, 1979). In only one of these studies (Schandry, 1978, p. 56) was Sokolov's (1963, pp. 62-63) finding of slower SCR habituation with weak stimuli clearly confirmed. As discussed by Graham (1973) and Turpin

Requests for reprints should be directed to G. Vossel, Psychologisches Institut der Universität Mainz, Abteilung Allgemeine Experimentelle Psychologie, Saarstr. 21, 6500 Mainz, West Germany. and Siddle (1979), there may be a number of reasons for the divergent results, including the fact that stimulus intensities have not been comparable across experiments. In addition, there is confusion about the construct validity of SCR-habituation measures.

One of the factors that strongly influences SCR habituation is electrodermal lability (Crider \& Lunn, 1971). Electrodermal lability, as indexed by the frequency of nonspecific electrodermal responses (NSRs), has been shown to be a rather stable individual difference characteristic (e.g., Bull \& Gale, 1973; Johnson, 1963; Lacey \& Lacey, 1958) which is highly correlated with SCR habituation (e.g., Coles, Gale, \& Kline, 1971; Rossmann, 1981; Siddle \& Heron, 1976). Leavy and Geer (1967) demonstrated that NSR frequency may well modify the effects of stimulus intensity on SCR habituation. In their study, a significant effect of stimulus intensity on number of trials to habituation could be obtained only by holding NSR frequency constant. Since Leavy and Geer had no complete record of NSRs prior to the onset of the first stimulus of the habituation experiment, they used NSR frequency over trials of the habituation experiment as the covariate. As the authors note, this procedure makes it impossible to control for the effects of stimulus intensity on NSRs. The present study was designed as a preliminary investigation of the effects of stimulus intensity on SCR habituation in electrodermally labile and stabile subjects selected on the basis of their NSRs prior to the habituation experiment. 


\section{METHOD}

Subjects

The subjects were 77 students ( 40 females, 37 males; age range 19-42 years), who were assigned randomly to one of six stimulusintensity conditions. Of these, 11 subjects were eliminated because of movement artifacts or equipment failures.

\section{Apparatus and Procedure}

Each group received 20 presentations of a $1,000-\mathrm{Hz}$ pure sine tone of $3 \mathrm{sec}$ duration at an intensity of $15,35,55,75,95$, or $110 \mathrm{~dB}$ (re: .0002 microbars). The tones were presented binaurally through stereo earphones (Beyer DT 220) with a constant interstimulus interval of $30 \mathrm{sec}$. Tone intensity was measured at the earphones using a Brüel and Kjaer Type 2203 sound-level meter (A scale). Ambient noise level at the side of the subject's head was $25 \mathrm{~dB}$; the earphones provided about $15 \mathrm{~dB}$ of attenuation at $1,000 \mathrm{~Hz}$. The stimuli were produced by a Wavetec Function Generator (Model 171) and attenuated by a Rohde and Schwarz standard attenuator (Type DPR). Stimulus duration and the interstimulus interval were controlled by a 5TI programmable control system (Texas Instruments).

Bipolar recording of skin conductance was accomplished using $\mathrm{Ag}-\mathrm{AgCl}$ electrodes which were attached to the medial phalanx of the index and second finger of the subject's left hand. A constant voltage of $.5 \mathrm{~V}$ (Lykken \& Venables, 1971) was applied across the electrodes. Skin conductance and presentation of stimuli were recorded on a Schwarzer polygraph (Varioskript V 822) on separate channels.

The subject was seated in a comfortable chair in a soundproof, temperature-controlled chamber (IAC, Type 403-A). All recording and programming equipment was located outside the room. The subjects were requested to wash their hands prior to connection with electrodes. They were informed that after a 5-min rest period they would hear a series of tones. The subjects were instructed to listen to the tones and remain as still as possible throughout the experiment. Following the last tone, the subjects were required to rate the tones in terms of loudness and unpleasantness.

\section{Scoring}

Artifact-free SCRs occurring from 1 to $6 \mathrm{sec}$ after stimulus onset were scored as stimulus-evoked responses and measured as change in micromhos.

Habituation of SCRs was assessed in a number of ways. First, habituation was said to have occurred when subjects displayed three consecutive nonresponses (e.g., Turpin \& Siddle, 1979). The trial number of the third nonresponse was designated as the trials to habituation score. Subjects whose last response was at Trial 18, 19, or 20 were assigned scores of 21,22 , or 23 , respectively. Second, the reciprocal of the frequency of SCRs greater than $.02 \mu \mathrm{hmos}$ to the first 10 stimuli was determined (Schandry, 1978 , p. 56). Third, intercept and slope scores were calculated for each subject by the regression of SCR amplitude on log stimulus number (a score and b score; cf. Montagu, 1963; Turpin \& Siddle, 1979).

Frequency of nonspecific responses (NSRs) during the 5-min prestimulation period was measured by counting the number of artifact-free fluctuations greater than $.02 \mu$ mhos.

\section{RESULTS}

\section{Definition of Labile and Stabile Groups}

The range of NSRs during the prestimulation period was from 0 to 70 , with a median of 8.5. Subjects below the median constituted the electrodermally stabile group (mean $=2.43$ ), and subjects above the median, the electrodermally labile group (mean =
24.76). In order to provide for equal cell size $(n=5)$ for each lability/intensity combination, six subjects (three labiles from the 15-, 55-, and 75-dB group; three stabiles from the 35-, 55-, and 110-dB group) were randomly eliminated from further analysis. The remaining 60 subjects constituted the sample.

\section{SCE Habituation}

A two-factor analysis of variance (lability $\times$ intensity) of the number of trials to habituation yielded significant effects for both lability $[F(1,48)=6.89$, $\mathrm{p}<.05]$ and intensity $[\mathrm{F}(5,48)=3.85, \mathrm{p}<.01]$. No interaction of lability $x$ intensity was found. Labiles showed overall greater resistance to habituation than stabiles. Pairwise comparisons of intensity means (Tukey test) revealed that the 35 -dB group differed significantly from the 55-, 95-, and 110-dB group. As can be seen in Figure 1, there was a tendency towards slower habituation with the $15-\mathrm{dB}$ tone as compared with the 35-dB tone, and greater resistance to habituation with further increasing tone intensity. Trend analysis of the data of labiles and stabiles combined, however, only revealed a significant linear trend $[F(1,54)=$ $9.80, p<.01]$, which accounted for $66 \%$ of the variance.

For the habituation measure proposed by Schandry (1978), that is, the reciprocal of the frequency of SCRs to the first 10 stimuli, a significant effect for intensity was obtained $[F(5,48)=2.55, p<.05]$. There were no other significant effects. The Tukey test indicated a significant difference between the 35and the 110-dB group. An inverted J-shaped relationship between intensity and habituation appeared (see Figure 2). Trend analysis of the combined data of

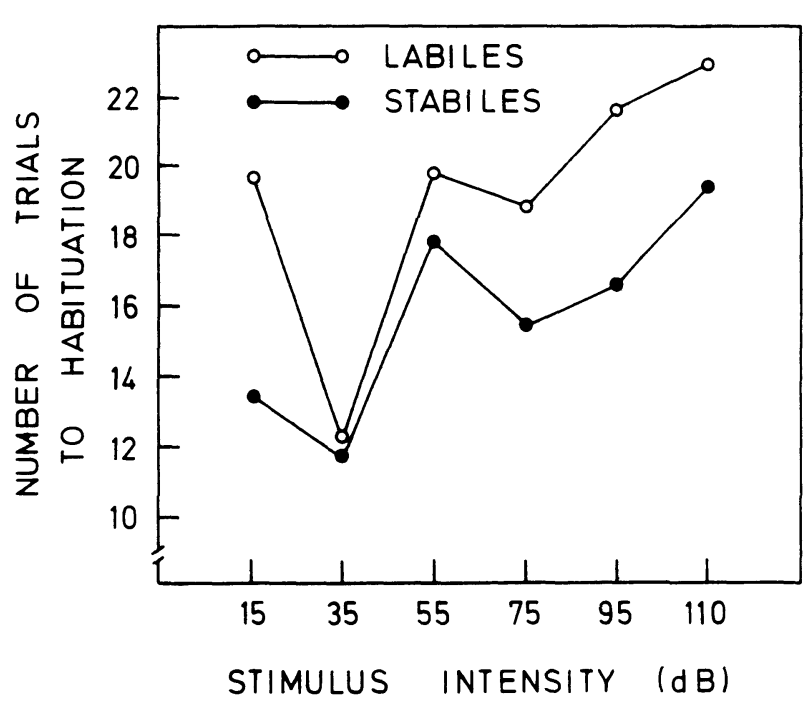

Figure 1. Number of trials to habituation for labile and stabile subjects plotted as a function of stimulus intensity (high values indicate slow habituation). 


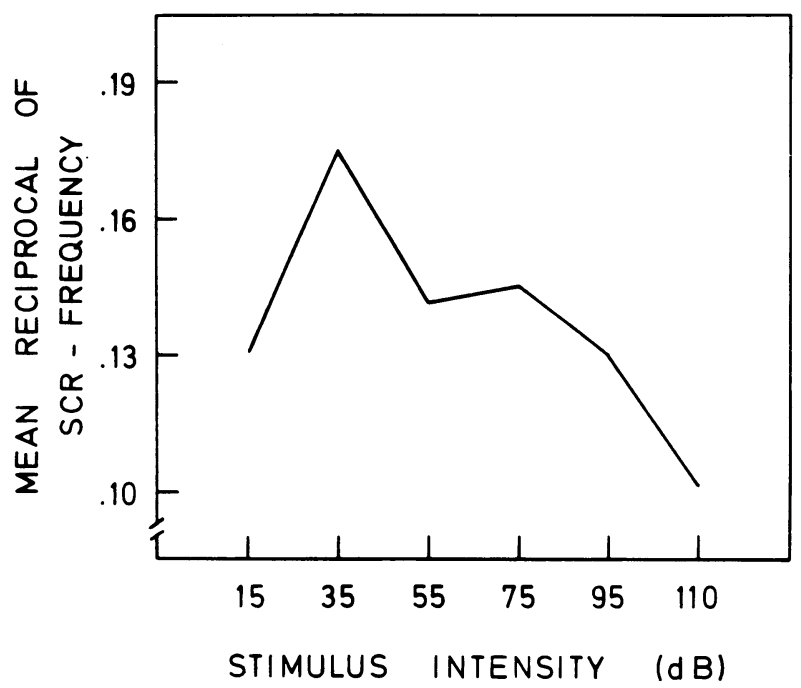

Figure 2. Mean reciprocal of SCR frequency to the first $\mathbf{1 0}$ stimuli plotted as a function of stimulus intensity (high values indicate fast habituation).

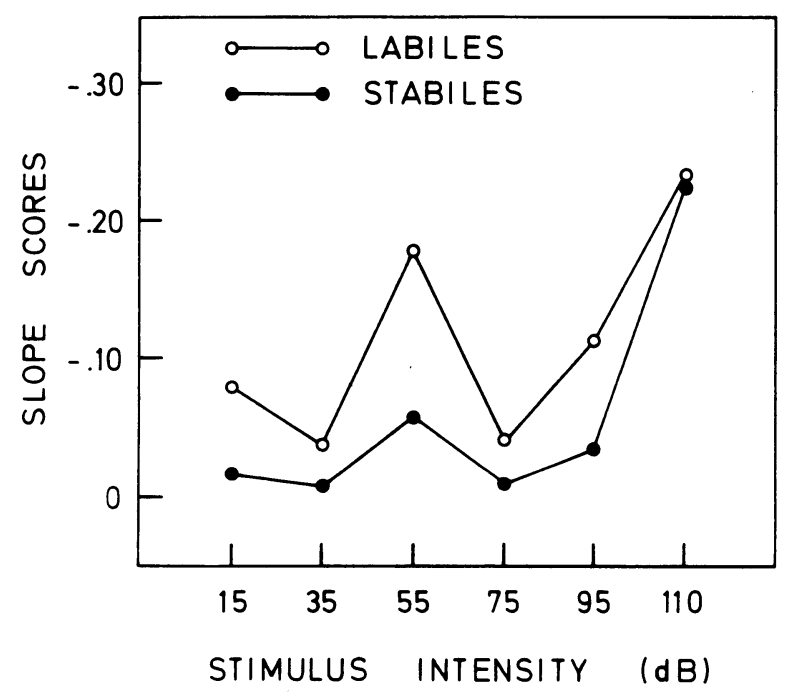

Figure 3. Slope scores for labile and stabile subjects plotted as a function of stimulus intensity (high negative values indicate fast habituation).

labiles and stabiles yielded significant linear $[F(1,54)=$ $4.56, \mathrm{p}<.05]$ and quadratic trends $[\mathrm{F}(1,54)=4.18$, $\mathrm{p}<.05$ ], which accounted for $41 \%$ and $36 \%$ of the variance, respectively.

Statistical analysis of the $b$ scores revealed reliable effects for both intensity $[F(5,48)=5.54, p<.01]$ and lability $[F(1,48)=4.10, p<.05]$. The lability $x$ intensity interaction did not reach statistical significance. Labiles showed overall faster habituation than stabiles. Pairwise comparisons of intensity means (Tukey test) showed that the 110-dB group displayed significantly higher negative $b$ scores than the remaining groups. Trend analysis of the data of both groups combined revealed significant linear $[F(1,54)=$ $11.84, p<.01]$, quadratic $[F(1,54)=5.43, p<.05]$, and cubic trends $[\mathrm{F}(1,54)=4.19, \mathrm{p}<.05]$, which accounted for $50 \%, 23 \%$, and $17 \%$ of the variance, respectively. It should be noted that the high negative slope scores of labile subjects under the 55-dB condition (see Figure 3) are probably due to the fact that the mean NSR frequency of this group was exceptionally high as compared with the means of the remaining labile groups. Nevertheless, a one-way analysis of variance did not reveal significant differences in NSR frequency between labile groups $[F(5,24)=1.05$, $\mathrm{p}>$.05].

Analysis of variance of the intercept scores (a scores) yielded significant effects for both intensity $[\mathrm{F}(5,48)=$ $5.28, \mathrm{p}<.01]$ and lability $[\mathrm{F}(1,48)=5.94, \mathrm{p}<.05]$. No lability $\times$ intensity interaction was found. Labiles had overall higher intercept scores than stabiles. The Tukey test indicated that the intercept scores of the 110-dB group were significantly higher than the intercept scores of the remaining groups. The results of trend analysis were almost identical with those obtained for $b$ scores and will not be reported in detail.

\section{DISCUSSION}

In the present experiment, significant effects of stimulus intensity on SCR habituation were obtained which were independent of electrodermal lability, as indexed by NSR frequency. This is not in agreement with the results reported by Leavy and Geer (1967). While they used NSR frequency over trials of the habituation experiment, the present study used NSR frequency from a prestimulation period. Further research should, therefore, be addressed to the question of whether the different methods employed to determine NSR frequency can account for the discrepant results.

For two of the three habituation measures of the present study, significant main effects of electrodermal lability were found. However, the analysis of the trials to habituation measure demonstrated overall slower habituation of labiles, whereas the analysis of the slope measure demonstrated overall faster habituation. The findings with regard to the effects of stimulus intensity were also ambiguous: The inverted J-shaped relationship that was found between SCR habituation and intensity for the reciprocal of SCR frequency to the first 10 stimuli, which is in agreement with Schandry's $(1978$, p. 56) results, could be taken as support of Sokolov's (1963) assertion of a nonmonotonic relationship between both variables. The same relationship, that is, slower habituation with the 15- $\mathrm{dB}$ tone as compared with the 35-dB tone followed by slower habituation with 
further increasing stimulus intensity, also seemed to appear for the number of trials to habituation, though trend analysis did not reveal a significant quadratic trend for intensity.

The findings for the slope measure, however, indicating faster habituation with increasing stimulus intensity, can be interpreted neither in terms of Sokolov's model nor in terms of the "dual-process" theory as formulated by Thompson and his colleagues (Groves \& Thompson, 1970; Thompson \& Spencer, 1966). Similar findings were reported by Schandry $(1978$, p. 53) and by Turpin and Siddle (1979). These results most probably may be attributable to the consistently found high negative correlation (up to $r=-.93$ ) between slope and intercept scores (Koriat, Averill, \& Malmstrom, 1973; Montagu, 1963; Siddle \& Heron, 1976). The intercept scores are usually regarded as an estimate of initial response amplitude (Montagu, 1963). As demonstrated in a number of studies (e.g., Jackson, 1974; Schandry, 1978), high-intensity stimuli elicit stronger initial response amplitudes than low-intensity stimuli. Considering the close relationship between intercept and slope that was also apparent in the present study, high-intensity stimuli, therefore, must necessarily be associated with high negative slope scores. The same argument would account for the higher negative slope scores of labiles, who were shown to display significantly higher intercept scores than stabiles.

There is, however, no readily available answer to the question of whether high negative slope scores are really indicative of fast habituation or whether slope scores must be regarded as a poor measure of habituation. Any answer to this question must concentrate on the issue of the relationship between slope and intercept scores: While they might be fortuitously related on the one hand, it might also be that the correlation between both scores is indicative of a common process underlying initial response amplitude and rate of habituation (see Koriat et al., 1973, for a fuller discussion). Nevertheless, any decision about the adequacy of SCR-habituation measures requires the development of theoretical formulations permitting the construct validation of these measures (cf. Siddle \& Heron, 1976).

\section{REFERENCES}

Bull, R. H. C., \& Gale, M. A. The reliability of and interrelationships between various measures of electrodermal activity.
Journal of Experimental Research in Personality, 1973, 6, 300-306.

Coles, M. G. H., Gale, A., \& Kline, P. Personality and habituation of the orienting reaction: Tonic and response measures of electrodermal activity. Psychophysiology, 1971, 8, 54-63.

CrIDER, A., \& LUNN, R. Electrodermal lability as a personality dimension. Journal of Experimental Research in Personality, 1971, 5, 145-150.

Graham, F. K. Habituation and dishabituation of responses innervated by the autonomic nervous system. In H. V. S. Peeke \& M. J. Herz (Eds.), Habituation (Vol. 1): Behavioral studies. London: Academic Press, 1973.

Groves, P. M., \& Thompson, R. F. Habituation: A dual-process theory. Psychological Review, 1970, 77, 419-450.

J ACKSon, J. C. Amplitude and habituation of the orienting reflex as a function of stimulus intensity. Psychophysiology, 1974, 11, 647-659.

Johnson, L. C. Some attributes of spontaneous autonomic activity. Journal of Comparative and Physiological Psychology, 1963, 56, 415-422.

Koriat, A., Averill, J. R., \& Malmstrom, E. J. Individual differences in habituation: Some methodological and conceptual issues. Journal of Research in Personaltiy, 1973, 7, 88-101.

LACEY, J. I., \& LACEY, B. C. The relationship of resting autonomic activity to motor impulsivity. Research Publications of the Association for Research in Nervous and Mental Disease, 1958, 36, 144-209.

Leavy, A., \& Geer, J. H. The effect of low level of stimulus intensity upon the orienting response. Psychonomic Science, $1967,9,105-106$.

LykKen, D. T., \& Venables, P. H. Direct measurement of skin conductance: A proposal for standardization. Psychophysiology, 1971, 8, 656-672.

Montagu, J. D. Habituation of the psycho-galvanic reflex during serial tests. Journal of Psychosomatic Research, 1963, 7, 199-214.

Raskin, D. C., Kotses, H., \& Bever, J. Autonomic indicators of orienting and defensive reflexes. Journal of Experimental Psychology, 1969, 80, 423-433.

Rossmann, R. Zur Konstruktvalidität der Habituations geschwindigkeit: Eine Analyse der Beziehungen zwischen verschiedenen Habituationsindizes der Orientierungsreaktion am Beispiel der Galvanischen Hautreaktion. Unpublished diploma thesis, University of Mainz, 1981.

SCHANDRY, R. Habituation psychophysiologischer Grössen in Abhangigkeit von der Reizintensität. Munchen: Minerva, 1978.

Siddle, D. A. T., \& Heron, P. A. Reliability of electrodermal habituation measures under two conditions of stimulus intensity. Journal of Research in Personality, 1976, 10, 195-200.

Sokolov, E. N. Perception and the conditioned reflex. Oxford: Pergamon Press, 1963.

Thompson, R. F., \& Spencer, W. A. Habituation: A model phenomenon for the study of neuronal substrates of behavior. Psychological Review, 1966, 73, 16-43.

Turpin, G., \& SiddeE, D. A. T. Effects of stimulus intensity on electrodermal activity. Psychophysiology, 1979, 16, 582-591.

(Manuscript received March 31, 1981; revision accepted for publication August 18, 1981.) 